\title{
Preface: Land use and climate change impacts on erosion and sediment transport
}

\author{
Sergey Chalov ${ }^{1}$, Valentin Golosov ${ }^{1,2,3}$, Adrian Collins ${ }^{4}$, and Mike Stone ${ }^{5}$ \\ ${ }^{1}$ Faculty of Geography, Lomonosov Moscow State University, Moscow, Russia \\ ${ }^{2}$ Kazan Federal University, Moscow, Russia \\ ${ }^{3}$ Insitute of Geography RAS, Moscow, Russia \\ ${ }^{4}$ Sustainable Agriculture Sciences Rothamsted Research, Okehampton, UK \\ ${ }^{5}$ Faculty of Environment, University of Waterloo, Waterloo, Canada \\ Correspondence: Sergey Chalov (srchalov@geogr.msu.ru) \\ Published: 1 August 2019
}

The papers presented in this volume were part of a joint symposium combining The Second International Young Scientists Forum on Soil and Water Conservation (WASWAC) and the International Commission on Continental Erosion (ICCE-IAHS) which was held on 27-31 August 2018, in Moscow. Contributions were invited on work that investigates fluvial processes including hillslope and gully erosion and sediment transport, as well as river channel changes and management, the influence of hydro-sedimentological processes operating at local to global scales, and those that compare the findings drawn from local and global studies. A particular focus of the papers in this new volume is to provide regional examples of sediment movement along the sediment cascade in Northern Eurasia. Most of these works report scientific studies across a territory which covers nearly one sixth of the land surface of the Earth. PIAHS volume permits wider dissemination of these regional studies. Collectively, the papers cover studies from the East European plain, Kola Peninsula Mountains, Central Siberian Plateau, and the Kamchatka peninsula, as well as river catchments in Japan and Italy.

This PIAHS volume continues the long-term tradition of stand-alone proceedings from meetings convened by the International Commission on Continental Erosion (ICCEIAHS). Since 1981, ICCE has arranged a sequence of conferences and published 36 proceedings - and this volume discusses the ICCE story through a detailed scientometric analysis of past ICCE activities (Bondarev, in this volume).
The first part of this volume comprises regional studies of soil and gully erosion (Sharifullin et al., in this volume; Gafurov et al., in this volume; Garankina et al., in this volume). The section also includes examples of an integrated approach to the study of sediment origin (Chalov et al., in this volume).

The second part of the volume is devoted to river process and connections with sediment transport issues. It includes novel studies of sediment yield presented by case studies from Italy (Porto and Callegari, in this volume), the Kamchatka peninsula (Kuksina, in this volume), Caucuses mountains (Tsyplenkov et al., in this volume) and channel erosion research (Golovlyov et al., in this volume; Fingert et al., in this volume; Kuznetsova et al., in this volume).

The third part of the volume links sediment transport processes and lake sedimentation, as well as environmental impacts. It mostly includes studies on the reconstruction of the long-term dynamics of sedimentation (Konoplev et al., in this volume; Wakiyama et al., in this volume; Garankina et al., in this volume), but also focuses on river runoff processes and salmon migration (Moreydo, in this volume).

The editors wish to thank all the contributing authors for their efforts and the numerous reviewers who contributed to the production of quality papers. Special acknowledgement is also extended to IAHS and WASWAC for facilitating the participation of young scientists. Additionally, this review is supported by RFBR project 18-05-60219. 